\title{
Study efficacy of new model of derivative clonazepam on hypnotic, sedative, blood hematology and evaluation reproductive function in male mice
}

\author{
Adnan. M. Jassim, ${ }^{a}$ Abbas. G. Hamad, ${ }^{a}$ Mohammed abed, ${ }^{\text {b }}$ Raad saad ${ }^{b}$ \\ aPharmacology Department, Veterinary Medicine College, biotechnology Al-Qasim Green University, Iraq.

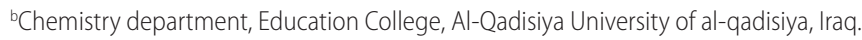 \\ Correspondence to Adnan Mansour Jasim (email: adnan.mansour81@gmail.com). \\ (Submitted: 20 August 2016 - Revised version received: 1 September 2016 - Accepted: 5 September 2016 - Published online: 26 December 2016)
}

\begin{abstract}
Objectives This study includes the investigation of hypnotic and sedative effect of new generation agent synthesis from parent clonazepam and evaluates adverse effect on the reproductive system and an attempt to improve hypnotic effect and lower toxicity.

Methods Sixteen male mice were randomly divided into four groups. The first day of treatment with single dose of $50 \mathrm{mg} / \mathrm{kg}$ intraperitoneal (IP) hypnotic effect then analgesic state was recorded in the 4th day of first week only after given $30 \mathrm{mg} / \mathrm{kg}$ orally, and then the experiment was persistent for 4 weeks to evaluate reproductive activity.

Result The effect of diazepam on biochemical blood parameters showed that there is a slight increase in the WBC number of clonazepam group and 88 compound while there is no significant difference at the probability level 0.05 or 0.01 , in 89 compound. RBC count in our result reveals a slight increase in 88 compound without significant difference than control. Our result shows significant increase in HB level in 88 compound to reach $13.18 \pm 0.40$ with no significant difference with control. PCV level reveals non-significant in all groups. Our results of the abnormal sperm morphology are shown after 4 weeks of the treatment

Conclusion clonazepam $\left(\mathrm{T}_{1}\right)$ and 88 compound $\left(\mathrm{T}_{3}\right)$ with high dose $50 \mathrm{mg} / \mathrm{kg}$ have good hypnotic action with complete muscle relaxant. In addition to all, agents have good analgesic effect but $T_{2}$ showed prominent result. Finally, clonazepam and its related agent 88,89 compound reveal adverse effect on reproductive function but may be very slightly in 94 compound.

Key words clonazepam, hypnotic, availability, abnormality
\end{abstract}

\section{Introduction}

Hypnotic drugs produce drowsiness and potentiate the onset and maintain the state sleep similar to natural sleeping. ${ }^{1}$ Actually, two stages of sleep are useful, (1) slow wave sleep and (2) rapid eye movement. Sedatives are the drugs that moderate the inhibition of central nervous system, moderate the excitement and calm the person. All hypnotic drugs in small dose possess sedative effect. ${ }^{2}$ Benzodiazepine derivatives are the most important sedatives and hypnotic drugs due to their large therapeutic index, lower side effect on cardiovascular and pulmonary system. These do not change the disposition of the treatment by microsomal enzyme induction. ${ }^{1}$ Benzodiazepines therapeutically used for as insomnia, sedatives, tranquillizer, anti-epilepsy and potent muscle relaxant of human and small animal. All agents of this group enhance the onset of sleep, alter the intermittent awakening and prolong the total sleeping period. The mechanism of action on the midbrain and limbic system that potentiates GABA ergic neurotransmitters via activation receptors lead to change ions CL inside cell due opening chloride channel that diminishes firing CNS cell. ${ }^{3,4-6}$ The duration of action of benzodiazepines is classified in three divisions according to persistent action in the body as long as acting which is persistent for 72 hours such as clonazepam, diazepam and flurazepam. Intermediate action persistent for more than 10 hours like lorazepam and temazepam, and the third divison include short acting type such as oxazepam that halfe life about 3-7 hours. ${ }^{-9}$ In fact, the drugs of choice of clonazepam in insomnia have psychological and physiological dependence. Actually hangover state was reported in patients consumed flurazepam. Benzodiazepines showed some pharmacological effect as bradykinin antagonist, antitumor and have some usefulness for Alzheimer's disease. The synthesis of compounds related to BDZS through Suzuki coupling reaction is a key step for the synthesis of new parent of arylclonazepam compound. ${ }^{10}$ Flumazenil used as antidote for clonazepam toxicity. Finally, the objective of study was to evaluate the efficacy of new parent model of clonazepam on sleeping time, hematological and sedative properties. Insomnia is a highly prevalent sleep disorder that frequently occurs in its acute type and occurs at $12-20 \%$ in its chronic type in a number of state. About $25-35 \%$ of the general people suffer from frequent sleeplessness. Sedative-hypnotic drugs, benzodiazepines and ramelteon also prescribed for insomnia associated with sleep onset. Sleep disorder induced by clonazepam has no effect on sleep duration. ${ }^{10}$ Clonazepam inhibits the release of acetylcholine in small domestic animals such as cat brain ${ }^{11}$ and decline prolactin release. Benzodiazepines inhibit thyrotrophic hormones release. ${ }^{12}$ Benzodiazepines acted via micromolar benzodiazepine binding sites as $\mathrm{Ca} 2+$ channel blockers. ${ }^{13}$ Finally, some report reveal that there is no effect on gamma-aminobutyric acid transaminase. ${ }^{26}$

\section{Materials and Methods}

General procedure was applied for the synthesis of the biaryl derivatives of clonazepam via Suzuki cross-coupling reaction to prepare 88,89 compound according to the previous report. ${ }^{16,30}$ 


\section{5-(3-Fluoro-biphenyl-2-yl)-7-nitro-1,3-dihydro- benzo[e] [1,4]diazepin-2-ol (88)according to 16,}

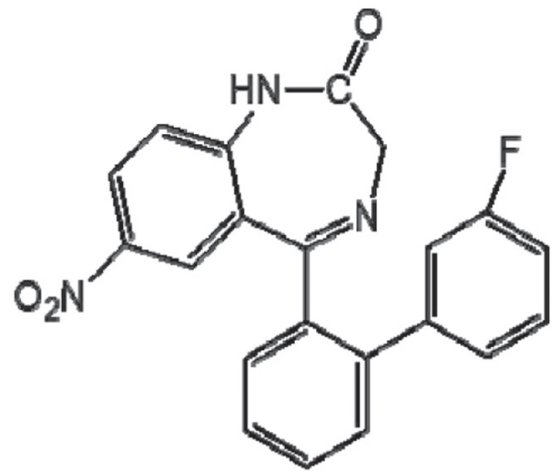

88

\begin{tabular}{ccccccc}
\hline Comp No. & Formula & M.Wt & m.p. $\left({ }^{\circ} \mathrm{C}\right)$ & Yield \% & Colour & $\mathbf{R}_{f}$ \\
\hline 88 & $\mathrm{C}_{21} \mathrm{H}_{14} \mathrm{FN}_{3} \mathrm{O}_{3}$ & 375.36 & 252 & 56 & Light brown & 0.52 \\
\hline
\end{tabular}

b-prepare 89 compound -5-Nitro-2'-(7-nitro-2-oxo-2,3-dihydro-1H-benzo[e] [1,4]diazepin-5-yl)-biphenyl-3-carboxylic acid (89).<smiles>O=C1CN=C(c2ccccc2-c2cc([N+](=O)[O-])cc([N+](=O)[O-])c2)c2cc([N+](=O)[O-])ccc2N1</smiles>

89

\begin{tabular}{ccccccc}
\hline Comp No. & Formula & M.Wt & m.p. $\left({ }^{\circ} \mathrm{C}\right)$ & Yield \% & Colour & $\mathbf{R}_{f}$ \\
\hline 89 & $\mathrm{C}_{22} \mathrm{H}_{14} \mathrm{FN}_{4} \mathrm{O}_{7}$ & 446.37 & $258-260$ & 65 & brown & 0.55 \\
\hline
\end{tabular}

\section{Animals}

Mature male mice weighting range from 55 to $80 \mathrm{~g}$ body weight and two month age were purchased from laboratory animal colony of Alqassim University/ Veterinary College. The animals were kept under normal conditions in plastic cages with 12 lights nearly and feed on pellets containing fat-free milk powder and water ad labium during the period of study.

\section{Drugs}

Clonazepam was purchased from neuraxpharm, Germany as standard.

\section{Animal experiments}

Sixteen male mice were randomly divided randomly into four groups:

Group 1(control): 4 mice as control

Group 2: 4 mice were administrated with clonazepam $\left(\mathrm{T}_{1}\right)$ in which $(30 \mathrm{mg} / \mathrm{kg} / \mathrm{TID}$ orally by stomach tube according to previous reports. $^{27,28}$

Group 3: 4 mice administrated with $(30 \mathrm{mg} / \mathrm{kg} /$ day b.w.) dose of 89 compound $\left(\mathrm{T}_{2}\right)$ were used for 4 weeks by stomach tube.
Group 4: 4 mice were administrated with 88 compound $\left(\mathrm{T}_{3}\right)$ at same dose $30 \mathrm{mg} / \mathrm{kg} /$ TID three times weekly for 4 weeks by stomach tube. Actually hypnotic effect of drugs was recorded in the first day of treatment with single dose of $50 \mathrm{mg} / \mathrm{kg}$ intra peritoneal (IP), and then analgesic state was recorded in the fourth day of first week only after given $30 \mathrm{mg} / \mathrm{kg}$ TID weekly. Later, the experiment persistent for 4 weeks for evaluating reproductive activity. Blood sample was collected after surgical opening of abdomen and chest under chloroform anesthesia finally the semen was collected after isolated tests from head of epididmis.

\section{Determination of organ weight to body weight ratio}

Organ weighed by sensitive balance after separated adipose tissues and washed with normal saline.

The organ weight to body weight ratio was calculated according to the following equation: the organ weight to body weight ratio $=$ weight of organ $(\mathrm{gm}) /$ weight of animal $(\mathrm{gm}) \times 100$.

\section{Determination of sperm viability}

Sperm suspension prepared by the addition $0.33 \mathrm{ml}$ of warm buffer solution at $37^{\circ} \mathrm{C}$. In this analysis, a drop from the sperm suspension mixed with one drop of eosin. After 30 seconds, a drop of nigrosin was added and mixed. Then a smear was made. The dead sperms showed pink color of the head while the viable sperm showed colorless under 40x. The data were tabulated in the form of percentage using the following formula:

Percentage of viable sperms $=$ No. of viable sperms $\times$ $100 \%$ /Total no. of dead and viable sperms. ${ }^{14}$

\section{Determination of sperms abnormalities}

In this analysis, 1-2 drops of suspension sperm were observed under light microscope. The smears were examined for abnormal morphology of the head, neck and tail. Then data were tabulated using the following formula:

Percentage of abnormal sperms $=$ No. of abnormal sperms $\times 100 \%$ / Total no. of normal and abnormal sperms. ${ }^{15}$

\section{Determination of clonazepam-Induced Sleeping Time}

This was the main test used for the assessment of the potentiating effect of agent that prolongs sleep induced by hypnotics like clonazepam. The body temperature of the mice was kept at $37^{\circ} \mathrm{C}$. The time from the administration of clonazepam or other agent to the loss of righting reflex was recorded to measure the latency to sleep onset. Then the mice were observed to stay on their backs on the pad and the time of regain of the righting reflex was recorded. The time from the loss to the regain of the righting reflex was indicated as the duration of sleep. The experiment was performed only between 9:00 A.M. and 7:00 P.M. Determination sedative (analgesic) activity of clonazepam was performed..$^{16,27,28}$

\section{Results}

The rate of the morphologically abnormal sperms increased highly significantly $(P<0.001)$ in the clonazepam $(30 \mathrm{mg} / \mathrm{kg}) .89$ compound $(30 \mathrm{mg} / \mathrm{kg})$, while 88 compound reveals accepted result in the improvement of live sperm, although a slight increase in seminal vesicle weight in fact important result represented by improvement and prolonged sleeping time with increased sedative effect at $50 \mathrm{mg} / \mathrm{kg} \mathrm{b}$ w in clonazepam and 88 compound. 


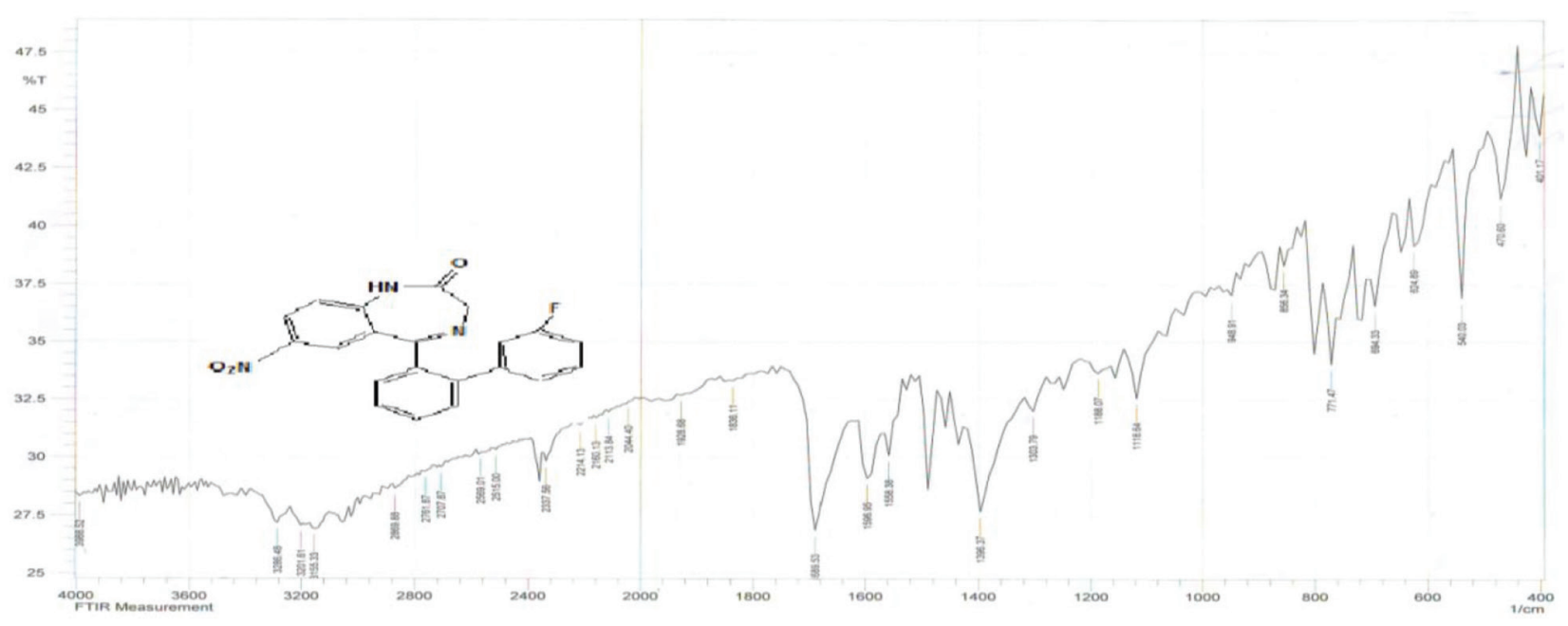

Fig 1. Refer to spectrum of (FT-IR) for 88 new compound.

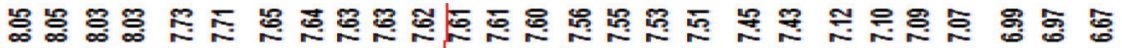

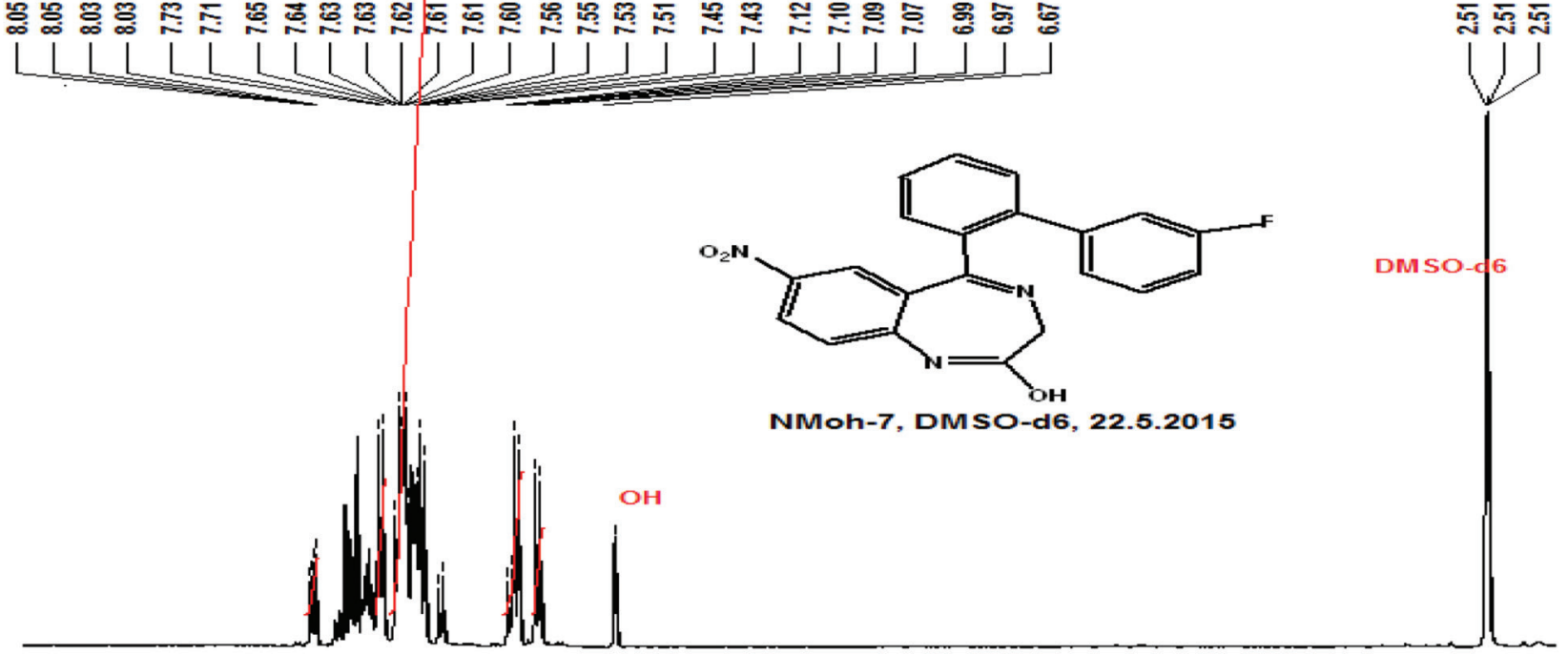

Fig 2. Showed spectrum ${ }^{1} H-N M R$ for 88 compound.

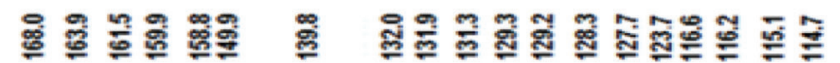
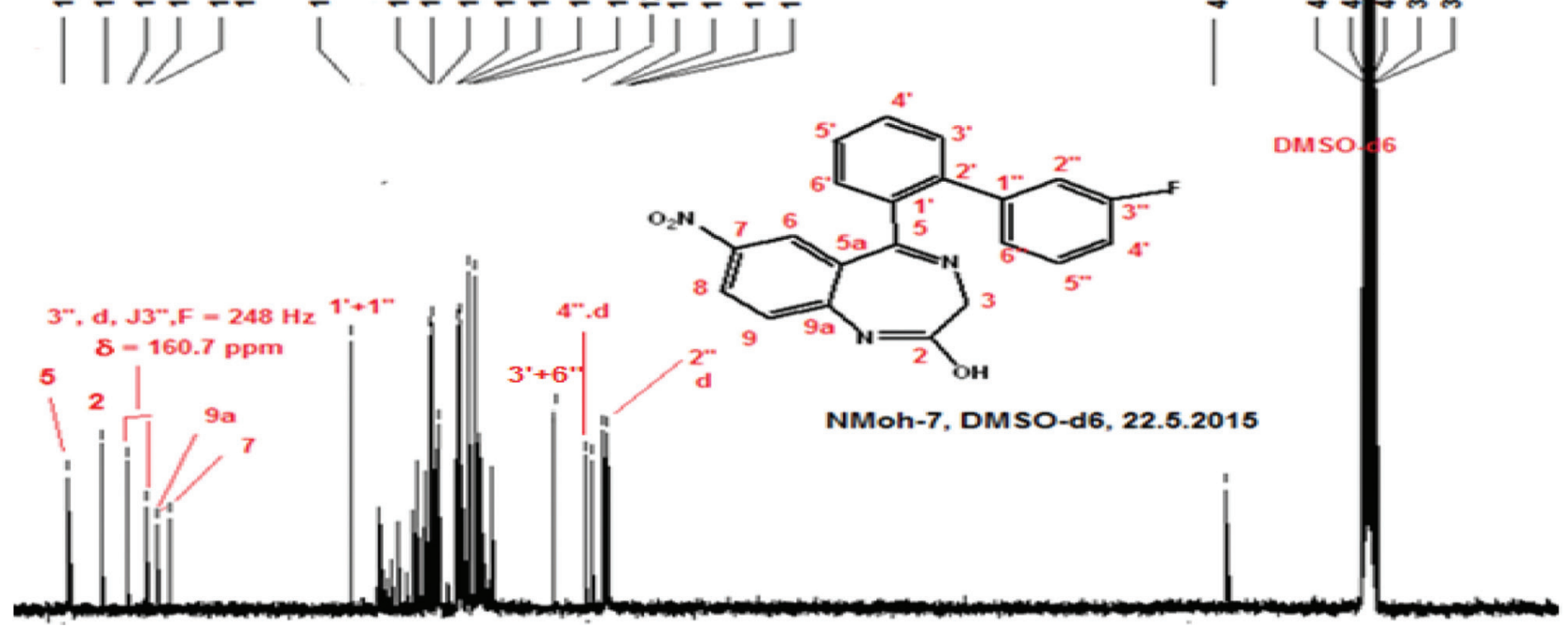

Fig 3. Refer spectrum of ${ }^{13} \mathrm{C}-\mathrm{NMR}$ for 88 compound. 


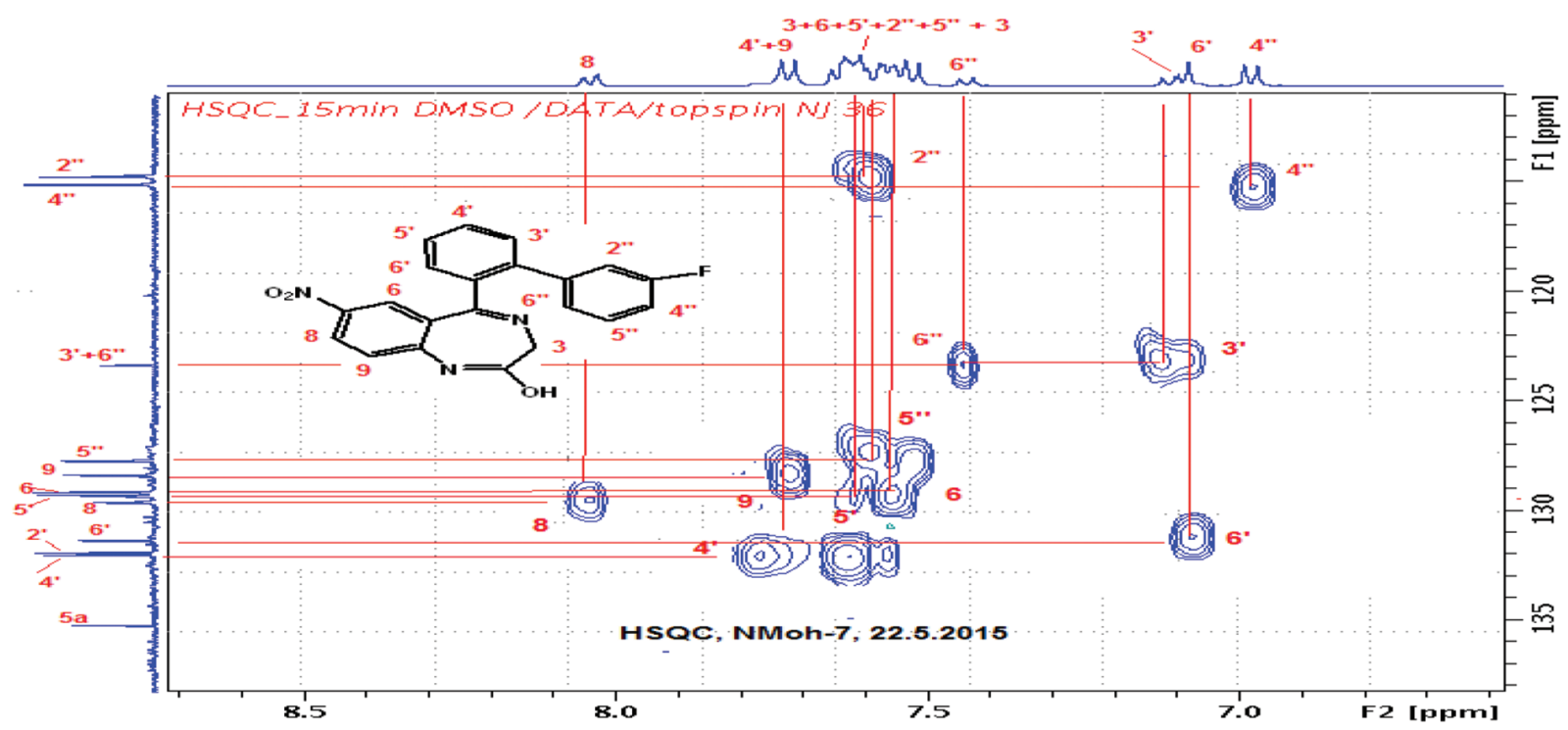

Fig 4. Refer spectrum of HSQC of 88 compound.

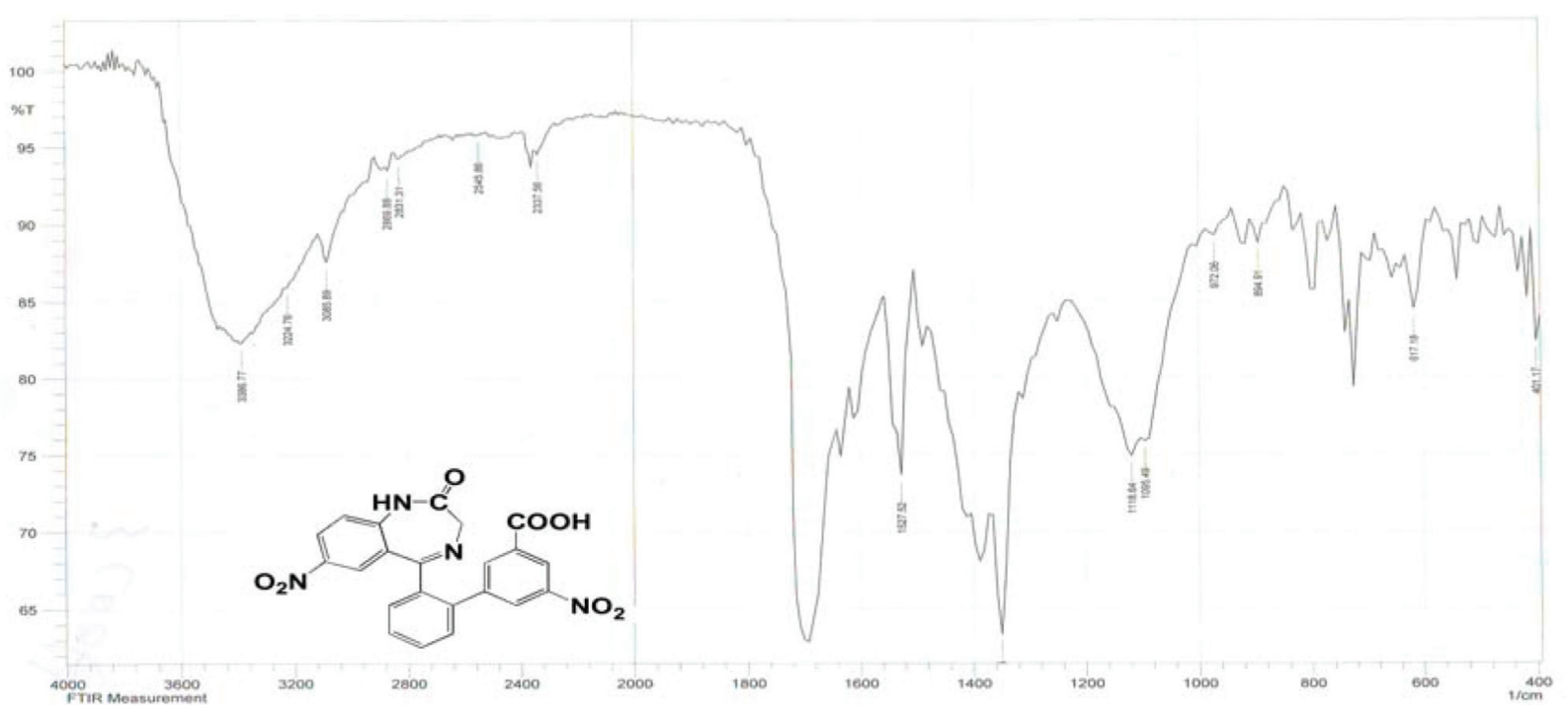

Fig 5. Spectrum of ${ }^{(\mathrm{fT}-\mathrm{RR})}$ for 89 compound.

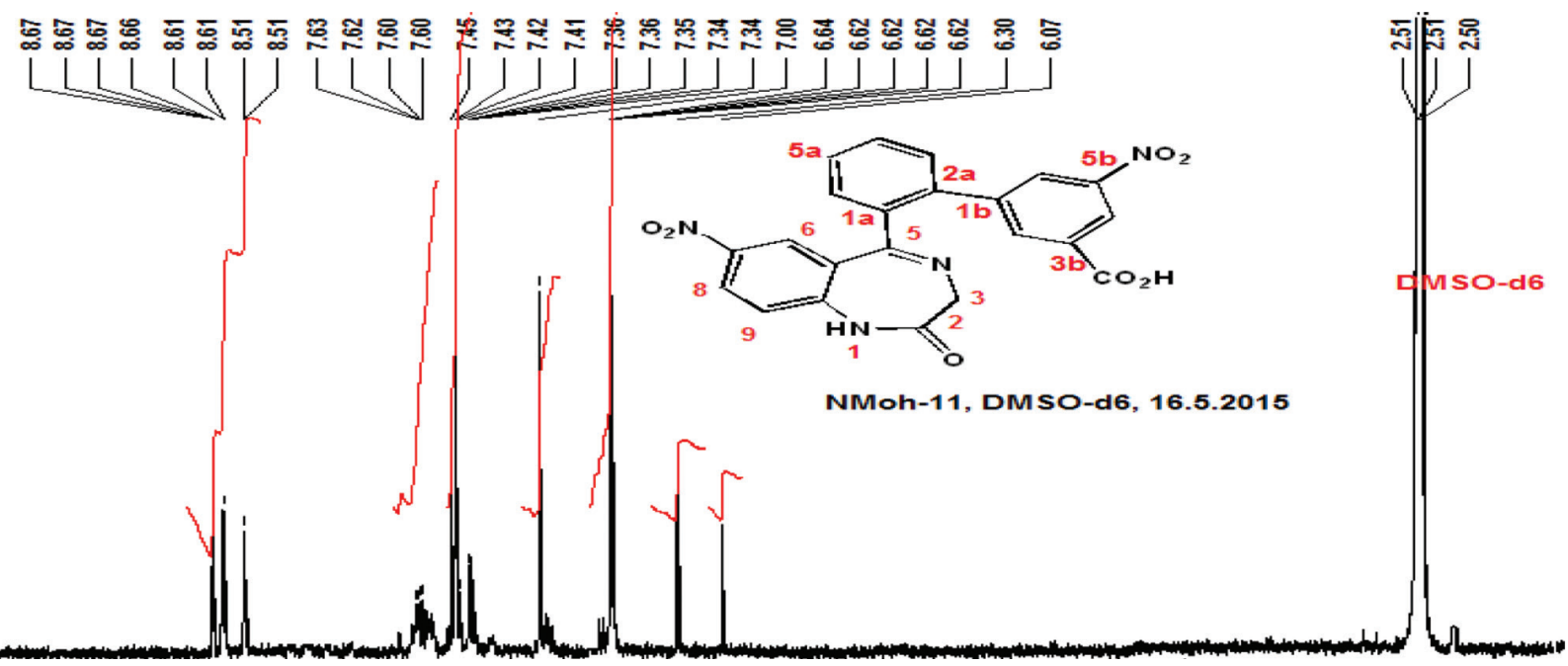

Fig 6. Refer spectrum of ' $\mathrm{H}-\mathrm{NMR}$ for 89 new compound. 
General procedure for the synthesis of the biaryl derivatives of clonazepam via SuZuki cross-coupling reaction according to moh a-prepare 88 and 89 compound.

The effect of diazepam on biochemical blood parameters (Table 1) showed a slight increase significant at $(P>0.05$ or 0.01 ) respectively in the WBC number of clonazepam group and 88 compound in comparision with the control, while no significant difference was found at at $(P>0.05$ or 0.01$)$ respectively, although group 88 compound $\left(\mathrm{T}_{3}\right)$ still near control to reach $2.58 \pm 0.11$. The RBC count in our result reveals slight increase in 88 compound without significant difference than control, and there is no significant difference $(P<0.005)$ between 89 compound and standard $(7.16 \pm 0.16$;
$7.09 \pm 0.19)$, respectively. Our result appears significant increase $(P<0.005)$ in the HB level in 88 compound to reach $13.18 \pm 0.40$ with no significant difference $(P<0.005$ and $0.01)$ with the control. The PCV level revealed no-significant difference in all treatment groups. The rate of the abnormal sperm morphology was shown after 4 weeks of the treatment. The percent of the morphologically abnormal sperms increased high significantly $(P<0.001)$ in the clonazepam (30 mg/kg), and 89 compound $(30 \mathrm{mg} / \mathrm{kg}$ ). The results were $(54.73 \pm 4.23,37.38 \pm 10.24 \%)$, respectively, compared to the 88 compound $(34.41 \pm 3.943 \%)$ group.

The percent of live sperm was increased in control group while the percent of active also showed in 88 compound to

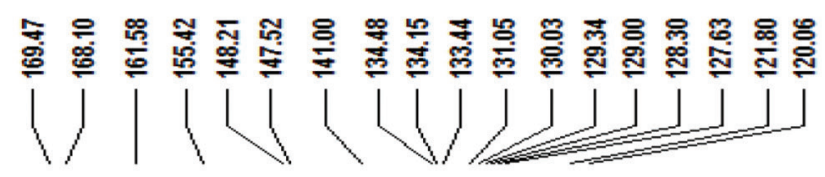

NMoh-11, DMSO-d6, 16.5.2016
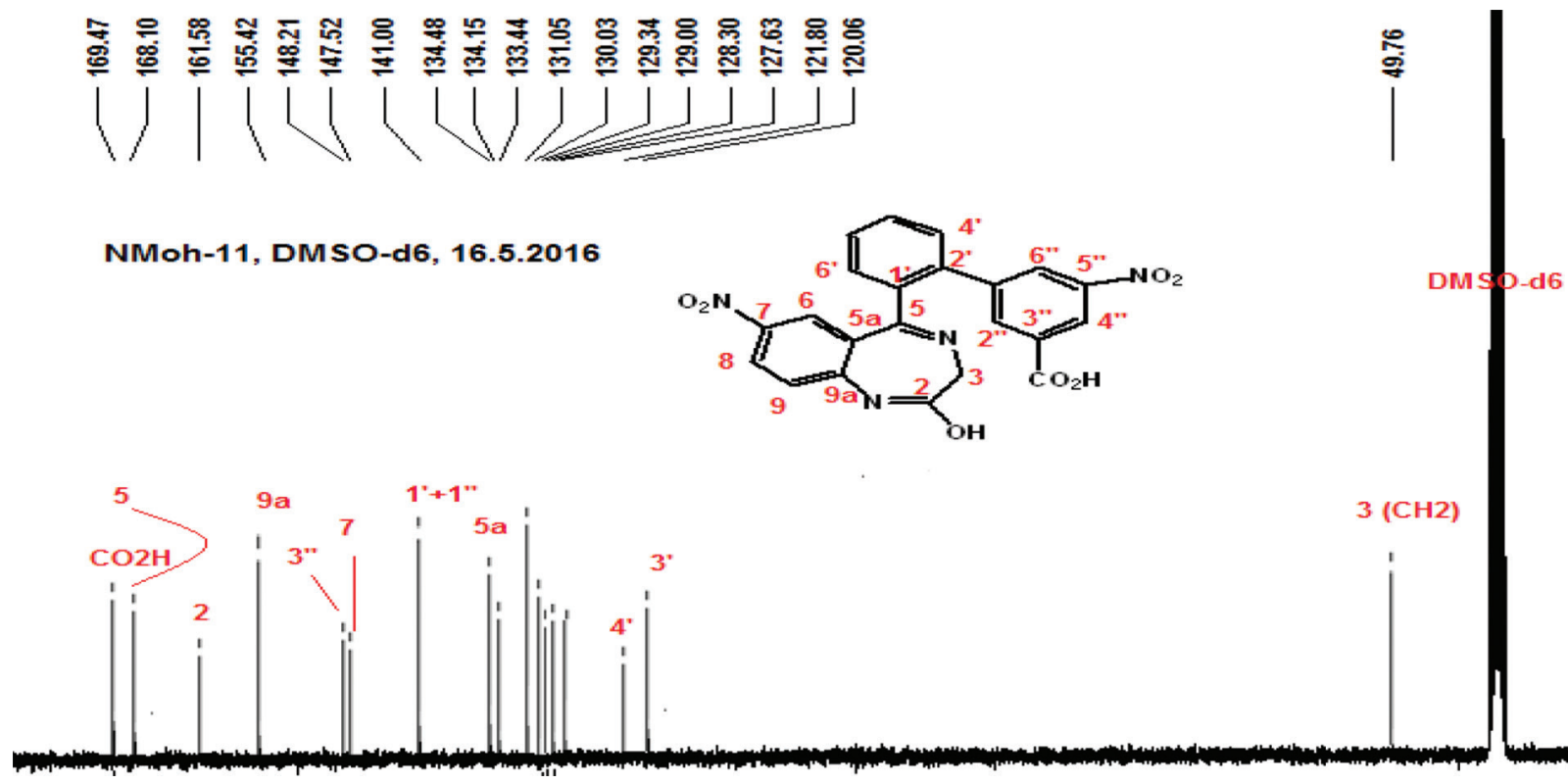

3 (CH2)

Fig 7. Spectrum of 13C-NMR of 89 compound.

\begin{tabular}{|c|c|c|c|c|}
\hline Traits & control & standard Clonazepam $\left(\mathrm{T}_{1}\right)$ & 89 compound $\left(\mathrm{T}_{2}\right)$ & 88 Compound $\left(\mathrm{T}_{3}\right)$ \\
\hline 1. No. of animals & 4 & 4 & 4 & 4 \\
\hline 2. WBC ${ }^{* *}$ & $2.7575 \pm 0.12 B$ & $4.3300 \pm 0.33 \mathrm{~A}$ & $2.5825 \pm 0.11 B$ & $3.9775 \pm 0.37 \mathrm{~A}$ \\
\hline 3. $\mathrm{RBC}^{*}$ & $7.9000 \pm 0.34 \mathrm{AB}$ & $7.0950 \pm 0.19 B$ & $7.1675 \pm 0.18 B$ & $8.1600 \pm 0.31 \mathrm{~A}$ \\
\hline 4. $\mathrm{Hb}^{* *}$ & $13.59 \pm 0.24 \mathrm{~A}$ & $11.25 \pm 0.32 B$ & $11.70 \pm 0.46 \mathrm{~B}$ & $13.18 \pm 0.40 \mathrm{~A}$ \\
\hline 5. PCV (NS) & $38.50 \pm 0.64 \mathrm{~A}$ & $41.25 \pm 2.49 \mathrm{~A}$ & $44.00 \pm 1.08 \mathrm{~A}$ & $40.75 \pm 2.01 \mathrm{~A}$ \\
\hline 6. Abnormal** & $16.67 \pm 1.65 C$ & $54.73 \pm 4.23 \mathrm{~A}$ & $37.38 \pm 10.24 \mathrm{AB}$ & $34.41 \pm 3.94 \mathrm{BC}$ \\
\hline 7. Livability* & $82.15 \pm 2.84 \mathrm{~A}$ & $67.57 \pm 2.90 B$ & $72.70 \pm 2.59 \mathrm{AB}$ & $77.50 \pm 5.72 A B$ \\
\hline
\end{tabular}

The trait carried out different letters horizontally indicated significant differences at probability level 0.05 or 0.01 . ${ }^{*}$, Significant differences at $0.05 ;{ }^{* *}$, Significant differences at 0.01 ; NS, non significant.

\begin{tabular}{lccccccc}
\multicolumn{6}{l}{ Table 2. Analysis variance of some biochemical blood traits in male mice administrated orally $\mathbf{3 0 ~} \mathbf{~ m g} / \mathbf{k g}$} \\
\hline \multirow{2}{*}{ Source of variance } & df & \multicolumn{7}{c}{ Sum of squares } \\
\cline { 3 - 8 } & & WBC ** & RBC * & Hb ** & PCV ( NS) & Abnormal ** & Livability \\
\hline Model & 3 & 9.11581875 & 3.37671875 & 15.42516875 & 61.2500000 & 2914.8465 & 471.1668 \\
Error & 12 & 3.32982500 & 3.08457500 & 6.52017500 & 142.5000000 & 1693.7379 & 672.1775 \\
Corrected total & 15 & 12.44564375 & 6.86129375 & 21.94534375 & 203.7500000 & 4608.5844 & 1143.3443 \\
\hline
\end{tabular}

*, Significant differences at 0.05; **, Significant differences at 0.01; NS, non significant. 
Table 3. Represent effect of clonazepam and new derivatives agent on organ body weight in gram

\begin{tabular}{lcccl}
\hline Organ & control & clonazepam & 89 compound & 88 compound \\
\hline Tests & $0.15 \pm 0.3 \mathrm{AB}$ & $0.13 \pm 0.33 \mathrm{~A}$ & $0.16 \pm 0.2 \mathrm{AB}$ & $0.19 \pm 0.1 \mathrm{~B}$ \\
Kidney & $0.23 \pm 0.01 \mathrm{~A}$ & $0.32 \pm 0.02 \mathrm{~A}$ & $0.30 \pm 0.03 \mathrm{~A}$ & $0.19 \pm 0.1 \mathrm{~A}$ \\
Spleen & $0.20 \pm 0.03 \mathrm{~A}$ & $0.17 \pm 0.01 \mathrm{~B}$ & $0.22 \pm 0.034 \mathrm{~A}$ & $0.25 \pm 0.022 \mathrm{~A}$ \\
Seminal & $0.23 \pm 0.011 \mathrm{~A}$ & $0.22 \pm 0.013 \mathrm{~A}$ & $0.22 \pm 0.01 \mathrm{~A}$ & $0.46 \pm 0.01 \mathrm{~B}$ \\
vesicle & & & \\
\hline
\end{tabular}

Table 4. Effect of clonazepam on analgesic and sleeping time min in mice at dose $50 \mathrm{mg} / \mathrm{kg} \mathrm{l.P.}$

\begin{tabular}{lrrc}
\hline Trial & Analgesia & Sleeping time & Muscle relaxant \\
\hline $\begin{array}{l}\text { Standard } \mathrm{T}_{1} \\
\text { (Clonazepam) }\end{array}$ & $54 \pm 1.95789 \mathrm{~A}$ & $21 \pm 3.69 \mathrm{~B}$ & +++ \\
$\mathrm{T}_{2}$ & $32.75 \pm 4.92231 \mathrm{~A}$ & $7.75 \pm 0.85 \mathrm{C}$ & + \\
$\mathrm{T}_{3}$ & $90 . \pm 4.92231 \mathrm{~B}$ & $42.50 \pm 1.25 \mathrm{~A}$ & +++ \\
\hline
\end{tabular}

reach $77.50 \pm 5.72$ and reduced in the clonazepam and 89 compound under $(P<0.005)$ to reach $67.57 \pm 2.90,72.70 \pm$ 2.59 respectively.

The trait carried out different letters horizontally indicated significant differences at the probability level 0.05 Similar capital litter reveal no significant difference. Our result in Table 3 reveals that there is significant difference between clonazepam and $\mathrm{T}_{3}$ group while there is no significant difference $P>0.05$ between control and $\mathrm{T}_{2}$

Our result reveals good analgesic and prolong sleeping time in clonazepam and 88 compound at the probability level 0.05 . The result in Table 4 shows that there is significant difference between $\mathrm{T}_{1}$ and $\mathrm{T}_{3}$ group in analgesic activity to reach at $54 \pm$ $1.95789,90 . \pm 4.92231$, respectively. On the other than, there is significant difference between all experimental group in sleeping time that showed perfect in $\mathrm{T}_{3}$ group to reach $42.50 \pm 1.25 \mathrm{~min}$.

\section{Discussion}

General procedure for the synthesis of the biaryl derivatives of clonazepam via Suzuki cross-coupling reaction to prepare 88, 89 compound according to the published articles. ${ }^{16,30}$ Using these procedures, two compound were prepared and then many tests were performed to record and named as new compound related to benzodiazepine group ${ }^{1} \mathrm{H}-\mathrm{NMR}{ }^{13} \mathrm{C}-\mathrm{NMR}$, according to action was classified as long acting type.

The data obtained from haematological study refer to significant increase $(P<0.01)$ under treatment with clonazepam and 89 compound $4.3300 \pm 0.33,3.9775 \pm 0.37$ respectively while 88 still with in normal limits. Erythrocyte result showed significant increase in 88 compound to reach $8.1600 \pm 0.31$. the result of hemoglobin indicate high increase in $88 \mathrm{com}$ pound to $13.18 \pm 0.40$ although mild reduction in standard and 89 compound. The date was concord with 35 reported significantly decreased hematopoietic elements (10-20\% total marrow cellularity in Table 3.

The results of our study reveals that 88 compound treatment caused an increase in body weight specially seminal vesicle. This was because of antiserotonin activity. Benzodiazepam group indicated in number of study reveal enlargement of seminal vesicle. This is in agreement with previous reports. ${ }^{17,18}$ The present study shows a decrease in testes and spleen weight in treated with clonazepam (Table 1). This

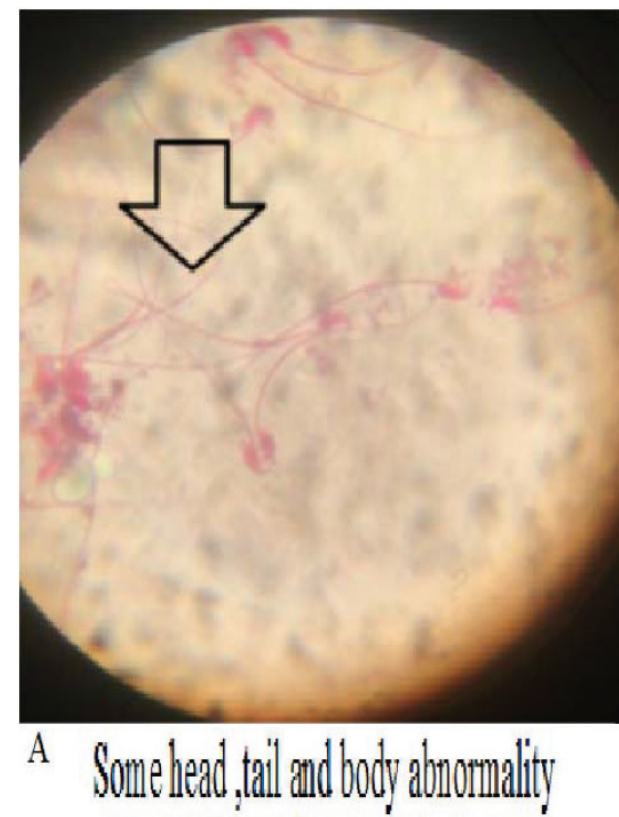

Fig 8. Sperm abnormality.

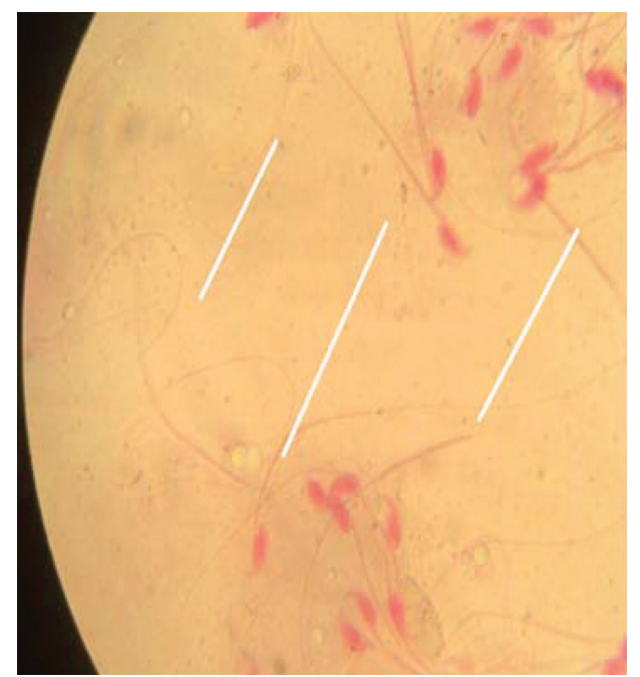

Fig 9. There is high percent of abnormalities and dead sperm listed with head loss and panana shape due to deformity.

could be attributed to a decrease in testosterone level, where testosterone has an important role in increasing the weight of the reproductive organs while the result was prominent in group 88 reveals significant increase to $0.19 \pm 0.1 .^{19}$ The reduction in the weight of the tests in the clonazepam groups may be due to the alteration of $\mathrm{LH}$ hormones as the conversion of cholesterol to pregnenolone is dependent upon pituitary $\mathrm{LH}^{20,21}$ It was reported that benzodiazepines cause direct inhibition to leydigcell and diminish the release of testosterone that is essential for development and divisions of spermatogonia. Spermatogenesis is affected by the hypothalamic-pituitary-testicular axis responsible for GNRH, LH, FSH and androgens. Thus, the action was evoked by clonazepam sperm. Viability might be potent linked to LH and FSH hormones that are also inhibited and highly influence sertoli cell functions in the sperm production.

Our result reveals a high significant increase in the rate of abnormality sperms include both the shape and size of the sperm head and tail. Due to clonazepam disruption, spermatogenesis 
processes in the semniferous tubules, epididymal functions and diminish testosterone via damage leydig cell that lead to the reduction of active sperm. . $2,23^{23}$

The development and the growth of male reproductive system and semniferous vesicles are dependent on the increase of testosterone level. Therefore any agent causing significant alteration in hormone leads to the significant percentages of abnormal sperm and reduces a live sperm. ${ }^{24,25}$ Our result shows that there was prolong sleeping time in 88 compound, and the period decreased in 89 compound in addition to good analgesic activity specially 88 compound.

Clonazepam and related agent 88 and 89 compound produce a higher incidence of drowsiness and sedation during all the period of study. The result agreed with the previous research report $^{27}$ indicating CNS depression caused by clonazepam will enhance as the dose increases towards the usual adult daily maintenance dose. Insomnia that is an important general problem caused by anxiety and classified in to three types. Transient insomnia can easily be treated by diphenhydramine and phenothiazine, and acute type persistent for more than weeks treated by benzodiazepam. Finally, chronic insomnia persists more than 3 months. Clonazepam and related compound 88,89 enhancing sleeping time by the effect on GABA neurotransmitters and may also increase the release of melatonin from the pineal gland that is essential for the regulation of sleeping. ${ }^{31}$

\section{Conflict of Interst}

None.

\section{References}

1. Vogel H, Wolfgang J, Scholkens A, Sandow J, Muller G, Vogel F. Hypnotic activity. Drug Discovery and Evaluation Pharmacological Assays, Hock, Franz J. (Ed.) 2002;2:495-496

2. Cascade $\mathrm{E}$, Kalali AH. Use of benzodiazepines in the treatment of anxiety. Psychiatry (Edgmont). 2008:5:21-22.

3 Dennis S, Charney S, John M, Adron H. Hypnotics and sedatives. In Goodmans and Gilman's, the pharmacological basis of therapeutics. 2006;11:401-429.

4. lader m, br j. clinical pharmacology. 2012;48:25-40.

5. Donoghue J, Lader M. Intl J Physch Clin Pra. 2010;14:78-87.

6. Crestani F, Löw K, Keist R, Mandelli M, Möhler H, Rudolph U. Molecular targets for the myorelaxant action of diazepam. Mol Pharmacol. 2001;59(3):442-445.

7. Robertson MD, Drummer OH. Postmortem drug metabolism by bacteria. J Forensic Sci 1995;40:382-386.

8. Meldrum BS. Drugs acting on amino acid neurotransmitters. Adv Neurol. 1986;43: 687-706.

9. Jenner P, Pratt JA, Marsden CD. Mechanism of action of clonazepam in myoclonus in relation to effects on GABA and 5-HT. Adv Neurol. 1986;43:629-643.

10. Andrew P, Owens A, Nadin A, Talbot A, Clarke E, Harrison T, et al. Bioorg Med Chem Lett. 2003;13:41-43.

11. Grandison L. Suppression of prolactin secretion by benzodiazepines in vivo. Neuroendocrinology. 1982;34:369-373.

12. Camoratto AM, Grandison L. Inhibition of cold-induced TSH release by benzodiazepines. Brain Res. 1983;265:339-343.

13. Petkov V, Georgiev VP, Getova D, Petkov VV. Effects of some benzodiazepines on the acetylcholine release in the anterior horn of the lateral cerebral ventricle of the cat. Acta Physiol Pharmacol Bulg. 1982;8:59-66.

14. Saadat P, Maryam JY, Mohammad AD. Effect of Phaleria macrocarpa on sperm characteristics in adult rats. Adv Pharm Bull. 2013;3:345-352.

15. Adnan M, hayder J, Hamad G. Study of the testicular damage induced by dianabol and its effect on morphological and histological changes in albino male rats IOSR. J Agri Vet Sci. 2016;8:24-32.

16. Jassim A, Almansory S, Hadi S, Alkareem GA. study comparison effect of a new naproxen modulated by addition of active group and a naproxen on the gastrointestinal safety and analgesic efficacy in male mice. Intl J Curr Res. 2015;7:23675-23687.

17. Taher $M$, Anber $Z$. Effect of diazepam on the reproductive system in male rats. World J Pharm Pharmaceut Sci. 2015;4:60-78.

18. Haleem DJ, Batool F. Regionally specific effects of diazepam on brain serotonin metabolism in rats: sustained effects following repeated administration. Life Sci. 1996;59:239-246.

19. Chowdhury M, Steinberger E. Differences of the effects of testosterone propionate on the production of LH and FSH. Act Endocinologica. 1976;82:688-690.

20. Reddy CM, Murthy DR, Patil SB. Antispermatogenic and androgenic activities of various extracts of Hibiscus rosa sinensis in albino mice. Ind J Exp Biol. 1997;35:1170-1174.

21. Nassem MZ, Patil SR, Patil SB. Antispermatogenic antiandrogenic activities of Momordica charantia (Karela) in albino rats. J Ethnopharmacol. 1998;61:9-16.

22. Bowman WC, Rand MJ. The reproductive system and drugs affecting the reproductive systems. Textbook of Pharmacology, 2nd edition. $1985 ; 20: 1-8$.

23. William KW. Hormones and hormone antagonists. In: Remington, The Science and Practice of Pharmacy, 20th edition, 2000;11:1390-1391.

24. Liu DY, Baker HW. Tests of human sperm function and fertilization in vitro. Fertil Steril. 1992;58:465-483.

25. Einstein R, Jones RS, Knifton A, Srarmer GA. Principles of veterinary therapeutics. Singapore, Longman Scientific and Technical. 1994:288-289.

26 Miller JA, Richter JA. Effects of anticonvulsants in vivo on high affinity choline uptake in vitro in mouse hippocampal synaptosomes. Br J Pharmacol. 1985;84:19-25

27. Wildin J, Pleuvry J, Mawer E, ONON T, Millington L. Respiratory and sedative effects of clobazam and clonazepam in volunteers. Br J Clin Pharmac. 1990;29:169-177.

28. Walle M, Walle B, Zerihun L, Makonnen E. Sedative-hypnotic like effect of the essential oil from the leaves of Myrtus communis on mice. Am J Biomed Life Sci. 2014;2:70-77.

29. Ngo Bum E, Ngoupaye G, Talla E, Dimo T, Nkantchoua GN, Pelanken M, et al. The anticonvulsant and sedative properties of stems of Cissuquadrangularis in mice African. J Pharm Pharmacol. 2008;2:42-47.

30. Salman MA, Abdul-Rida NA. Synthesis of new derivatives of aryl-clonazepam via Suzuki cross-coupling reaction. Eur J Chem. 2016;7:2152-2155.

31. Lin CM, Chiu HY. RNMS and Christian Guilleminault. Melatonin and REM behavior disorder. J Sleep Disorder Ther. 2013;2:2-9. 